\title{
We must not forget that $99 \%$ of the total number of molecules present in a living organism is water
}

\author{
Parvez I. Haris \\ Faculty of Health \& Life Sciences, De Montfort University, The Gateway, Leicester, LE1 9BH, United \\ Kingdom \\ E-mail:pharis@dmu.ac.uk
}

In recent years there has been a tremendous growth in the generation of biological data especially genomics and proteomics data. For example, there are 106 billion nucleotide bases from 108 million individual sequences deposited in the GenBank [2]. Progress is being made in our understanding of the structure and function of different genes and proteins and many new genomic and proteomics projects are being initiated around the world. In contrast, very little effort is being devoted to understanding the role of the molecule that comprises $99 \%$ of the total number of molecules in a living organism. Perhaps less than $1 \%$ of the total research on molecules, present in biological systems, is dedicated to the water molecule. In my view, this lack of interest in water may be responsible for the slow progress in our understanding of biochemical mechanisms and disease processes. The statements made by the Nobel Prize winner Albert Szent-Gyorgyi regarding water are worthy of being remembered [5]. He wrote "Sixty years of research has taught me to look upon water as part and parcel of the living machinery, if not the hub of life... Life is water dancing to the tune of solids. That biologists forgot about it is no more than natural. According to Sir Oliver Lodge the last thing a deep sea fish could discover is water."

It is not easy for those using spectroscopic techniques for analysis biological systems to forget about water. They at least have to deal with the "problem" of water overlapping with signals from their molecules of interest. This is especially the case for those using techniques such as infrared and NMR spectroscopy. As an example, from an early stage of my own research career [see Fig. 1], I had to address the absorption of water in the mid-infrared spectrum of biological systems [1]. One of the "solutions" to overcome this problem was to record the spectrum of water and subtract it from the spectrum of the biological sample. Other "solutions" have included measuring biological samples in deuterium oxide $\left({ }^{2} \mathrm{H}_{2} \mathrm{O}\right)$, organic solvents or in the dry state [3]. In reality, none of these are true solutions as the structure of the water $\left(\mathrm{H}_{2} \mathrm{O}\right)$ molecules and their impact on the structure of the biological molecules cannot be fully taken into consideration through these procedures. Fourier transform infrared (FTIR) microspectroscopy is becoming a popular tool for analysis of biological tissues and researchers are looking for ways to analyse these samples in a more physiologically relevant condition. Much of the current studies are performed with dried or fixed biological samples in order to overcome the problem of overlapping 


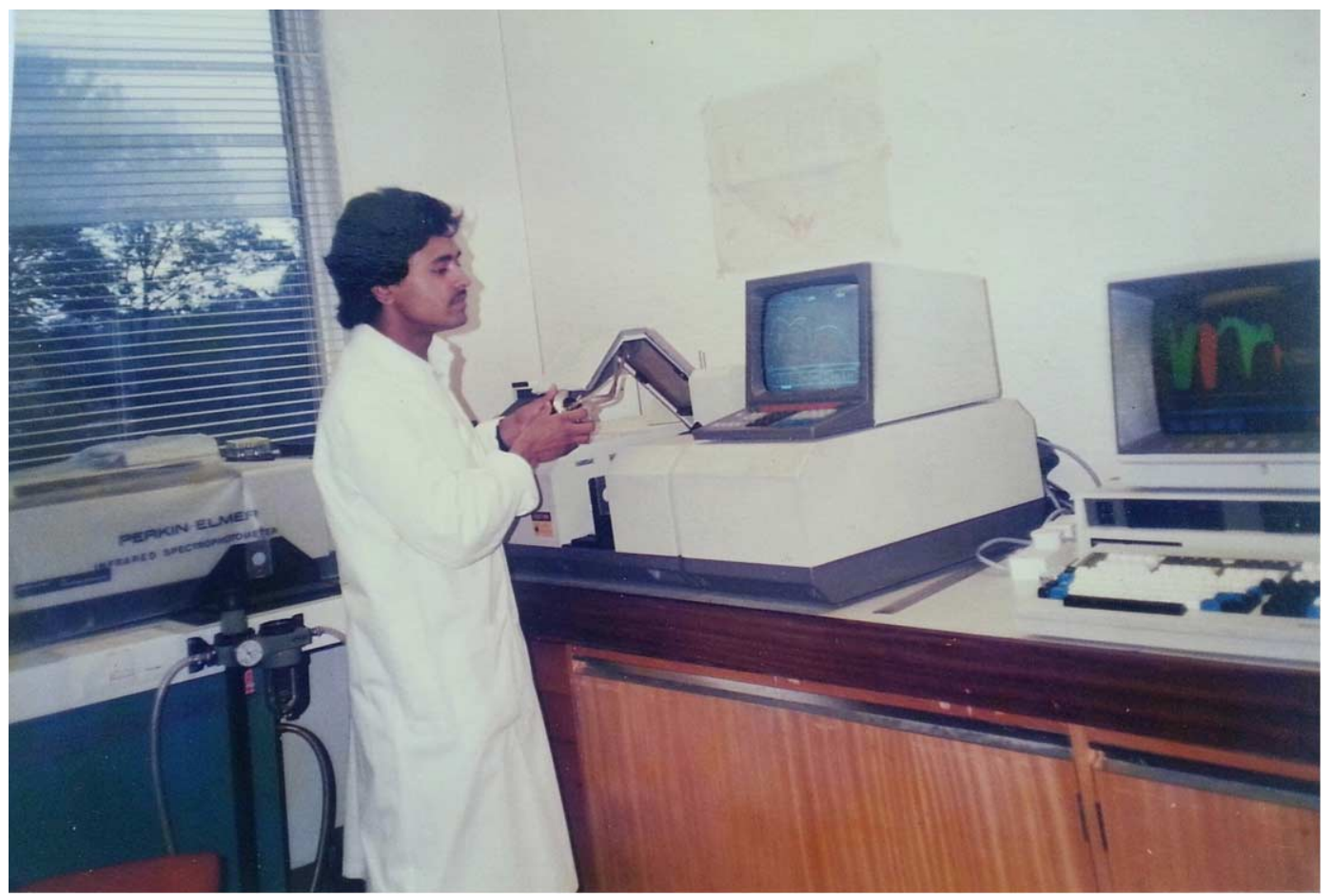

Fig. 1. Author of this article recording FTIR spectra of $\mathrm{H}_{2} \mathrm{O}$ at the Royal Free Hospital School of Medicine, University of London. Spectra of $\mathrm{H}_{2} \mathrm{O}$ and ${ }^{2} \mathrm{H}_{2} \mathrm{O}$ can be seen displayed on a computer attached to the FTIR spectrometer (photograph taken in 1987).

water absorbance from the cellular media. This issue of Biomedical Spectroscopy and Imaging contains a review article that discusses the application of FTIR microspectroscopy for studying single living cells [4]. It focuses on the evolution of the technique for deriving more physiologically relevant information by avoiding the need to isolate cells from their natural environment or subjecting them to stressful conditions. It is good to see efforts being made to develop technologies that enable spectroscopists to carry out their analysis without having to remove water molecules that are present in their biological samples. In my view, all researchers engaged in the analysis of biological systems must do more to consider water and its pivotal role as a molecule of life.

\section{References}

[1] A. Barth and P.I. Haris, Infrared spectroscopy - Past and present, in: Biological and Biomedical Infrared Spectroscopy, A. Barth and P.I. Haris, eds, IOS Press, Amsterdam, 2009, pp. 1-52.

[2] D.A. Benson, I. Karsch-Mizrachi, D.J. Lipman, J. Ostell and E.W. Sayers, GenBank, Nucleic Acids Research 38(Database issue) (2010), D46-D51.

[3] P.I. Haris and F. Severcan, FTIR spectroscopic characterization of protein structure in aqueous and non-aqueous media, Journal of Molecular Catalysis B: Enzymatic 7(1) (1999), 207-221. doi:10.1016/S1381-1177(99)00030-2.

[4] S. Sabbatini, C. Conti, G. Orilisi and E. Giorgini, Infrared spectroscopy as a new tool for studying single living cells: Is there a niche?, in: Biomedical Spectroscopy and Imaging, 2017.

[5] A. Szent-Gyorgyi, The Living State: With Observations on Cancer, Academic Press, New York, 1972, p. 9. 